\title{
Canine Feeding Practices in Urban Punjab - A Concern
}

\author{
Prabhjot Kaur Sidhu*, Anant Simran Singh, Ankita Singla and Prabhjinder Singh
}

Khalsa College for Veterinary and Animal Sciences, Amritsar, Punjab, India

*Corresponding author

\section{A B S T R A C T}

The use of nutritionally complete and balanced food has been cited as a contributing factor for longer, healthier life spans in pets. The present study was conducted on the dog owners from Bathinda and Ludhiana districts of Punjab during 2018. A total of 54 owners were

\section{Keywords}

Feeding practices, Dog owners, Urban Punjab, Canines

Article Info

Accepted:

04 July 2019

Available Online:

10 August 2019 interviewed randomly with a set of 20 variables regarding different aspects of dog feeding and independent variables viz., age, education, etc. The statistical analysis of data revealed that 57.5 percent of the dog owners were young (18-31 years old) and 61 percent of respondents had their qualification of senior secondary or higher level. About 32.5 percent of farmers preferred small breeds over large ones. About 75.9 percent of dogs were fed only home-cooked food, 7.4 percent were fed only commercial food whereas 16.6 percent were fed a mixture of commercial and home-cooked food. About 53.7 percent of dogs were fed milk as a separate meal in addition to their normal diet and 24.1 percent of dogs received dietary supplements. The vitamins were the most commonly used supplement in adult dogs (18 percent) whereas the most common supplement used in puppies was calcium and phosphorus (46.5 percent). Only 15 percent dog owner were aware about balance feed for their pets. Seventy three per cent of owner's regarded their dogs' as being at an ideal weight, while 27 percent regarded their dogs as overweight. This study was revealed an insight into the basic feeding practices followed by dog owners in the urban areas of Punjab.

\section{Introduction}

Dog, considered as the best among the other companion animals, has been associated with mankind since ages.

Apart from companionship and enjoyment or as a household animal, dogs are also kept for other important works like sniffer dogs, rehabilitation purposes; also make great guides and assistant for people with physical disabilities and mental disorders. Also, during the last decade, the interest of the human population has increased towards the keeping of companion animals like a dog (Kumar et al., 2014).

During the early days, pets have been fed mostly leftovers of human food. Dogs have specific nutritional requirements that must be considered in relation to age, condition, weight and physical activity. Kraft (1998) reported that the use of nutritionally complete and balanced commercial diets has been cited as a contributing factor for longer life spans in pets. 


\section{Materials and Methods}

The present study was conducted on the dog owners from Bathinda and Ludhiana districts of Punjab during 2018. A total of 54 owners were interviewed randomly with a pre-tested questionnaire. The pattern of questions followed was to find out the proportion of dogs being fed commercial or homemade food; how much of the diet consisted of commercial or homemade food, the general components of a homemade diet (mainly chapatti; mixture of both chapatti and rice) and how many dogs were fed milk as a separate meal as well as the proportion of diets supplemented with mineral and vitamin supplements as proportional to their body weight.

The collected data was tabulated and analyzed for frequency distribution and percentile by using the software package SPSS version 20.0

\section{Results and Discussion}

The statistical analysis of data revealed that 57.4 percent of the dog owners were young (18-31 years old). 38.9 percent of the respondents had their qualification of matric or under matric level whereas 61.1 percent of respondents had their qualifications of senior secondary or higher level (Table 1).

This study indicated that majority of owners were young and 42.6 percent owners having secondary education and most of the owners kept dogs for the fancy purpose only. It was observed thatthey can be given more knowledge regarding the nutrient requirements as different types of breeds require different kinds of nutrients according to their body weight and activity (Table 2).

Owners were questioned regarding the body condition of their pets; 27.8 percent regarded their pets as obese or overweight whereas 72.2 percent of the owners regarded their dogs as being of an ideal weight. Freeman et al., (2006) reported that only 32.3 percent of owners regarded their dogs as obese or overweight, but $<1$ percent these owners considered obesity to be a health problem. A similar type of study was conducted by Seneviratne et al., (2016) showed only 22 percent owners considered their pets obese or overweight.

So it would be useful to compare the proper body score of dogs with owners' perception of body weight in further studies. About 33.3 percent of dog owners preferred small breeds over large ones. The reason behind this maybe these breeds are easy to handle so proper care can be taken off (Table 3) whereas most of the dog owners also rearing larger breeds in urban areas due to security purposes.

\section{Feeding practices}

The scenario of feeding practices in the case of developed countries like the United States and Australia revealed that more than 90 percent of dogs were receiving commercial food which forms 50 percent of their diet (Laflamme et al., 2008). Homemade diets are often fed due to the lack of availability of commercial diets and the increased cost as well as the precedent of feeding human leftovers to pets.

The change in lifestyles in the cities and the increase in pedigree dog breeds, as well as the increasing availability of commercial foods over the last 15 years, means that owners are more likely to be interested in commercial pet foods. However the results were quite opposites with more than 70 percent of dog owners preferring homemade food over the commercial one (Fig. 1). Among the homemade foods, chapati was most commonly fed than rice or a mixture of chapati and rice (Fig. 2). 
Table.1 Different age groups of the dog owners

\begin{tabular}{|l|l|l|l|}
\hline $\begin{array}{l}\text { Sr. } \\
\text { No. }\end{array}$ & Age group of the owners & Frequency distribution(N=54) & $\begin{array}{l}\text { Percentage } \\
(\boldsymbol{\%})\end{array}$ \\
\hline 1. & Below 18 years & 3.0 & 5.6 \\
\hline $\mathbf{2 .}$ & 18-31 years & 21.0 & 57.4 \\
\hline 3. & 31-50 years & 12.0 & 22.2 \\
\hline 4. & Above 50 years & 8.0 & 14.8 \\
\hline
\end{tabular}

Table.2 Educational status of the dog owners

\begin{tabular}{|l|l|l|l|}
\hline $\begin{array}{l}\text { Sr } \\
\text { No }\end{array}$ & $\begin{array}{l}\text { Educational status of the } \\
\text { owners }\end{array}$ & Frequency distribution(N=54) & $\begin{array}{l}\text { Percentage } \\
(\%)\end{array}$ \\
\hline 1. & Under matric & 7.0 & 13.0 \\
\hline 2. & Matric & 14.0 & 25.9 \\
\hline 3. & Senior secondary & 23.0 & 42.6 \\
\hline 4. & Graduate or above & 10.0 & 18.5 \\
\hline
\end{tabular}

Table.3 Owners perception and preference regarding body weight and breed of their dogs

\begin{tabular}{|l|l|l|l|}
\hline $\begin{array}{l}\text { S. } \\
\text { No. }\end{array}$ & Condition of the pets & $\begin{array}{l}\text { Frequency } \\
\text { distribution(N=54) }\end{array}$ & $\begin{array}{l}\text { Percentage } \\
(\mathbf{\%})\end{array}$ \\
\hline $\mathbf{1 .}$ & Is your pet overweight & & \\
\hline & Yes & 15.0 & 27.8 \\
\hline & No & 39.0 & 72.2 \\
\hline $\mathbf{2 .}$ & Preferred breed & & \\
\hline & Small & 18.0 & 33.3 \\
\hline & Large & 36.0 & 66.7 \\
\hline
\end{tabular}

Fig.1 Distribution of diet types fed to dogs in this study

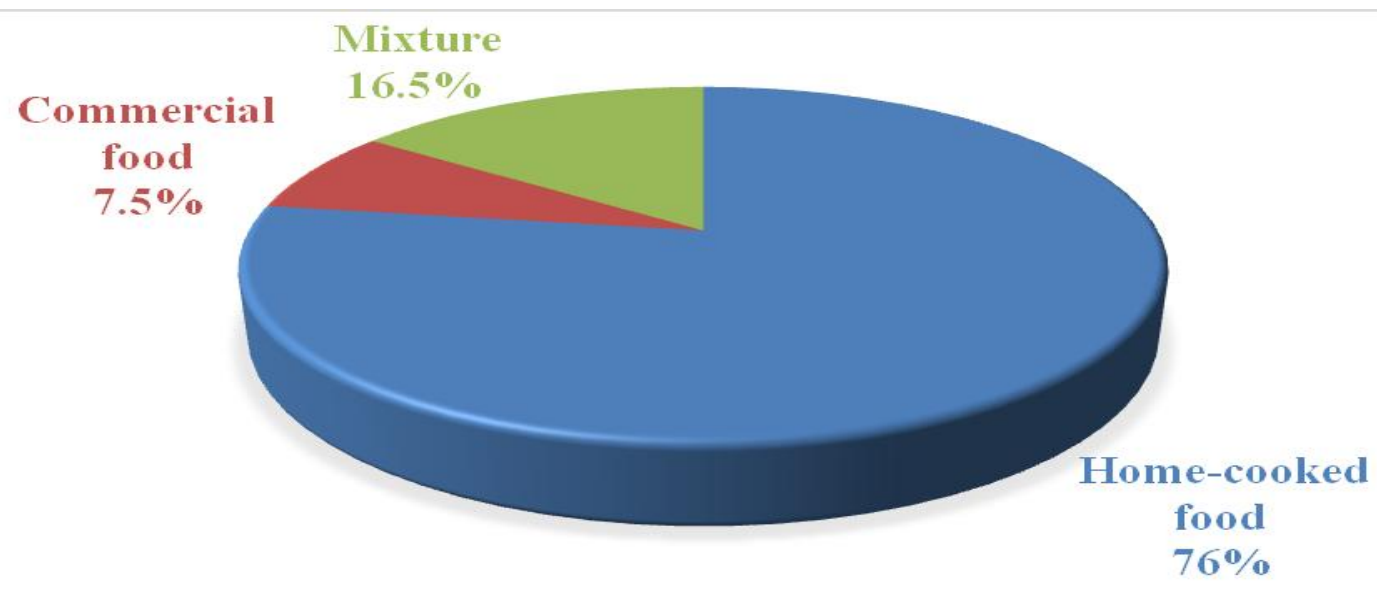


Fig.2 Ingredients of diet fed to dogs in this study

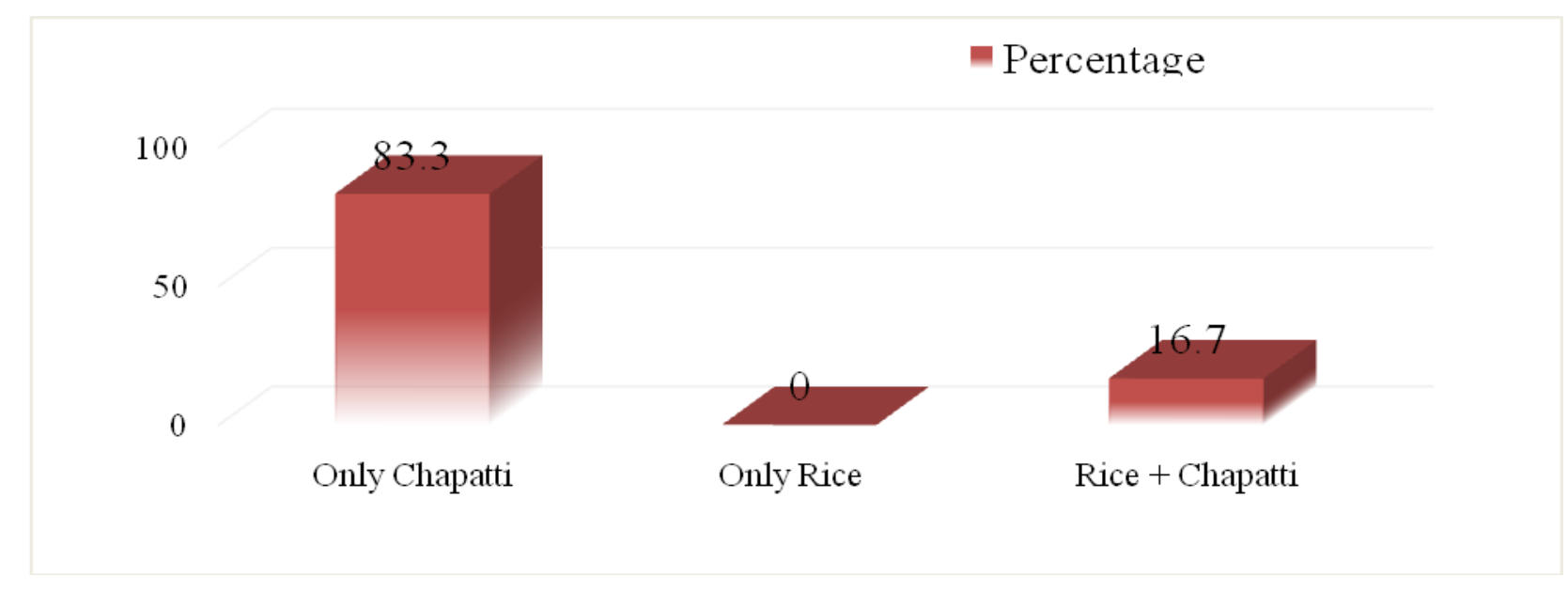

Fig.3 Awareness about the balanced feed fed to dogs

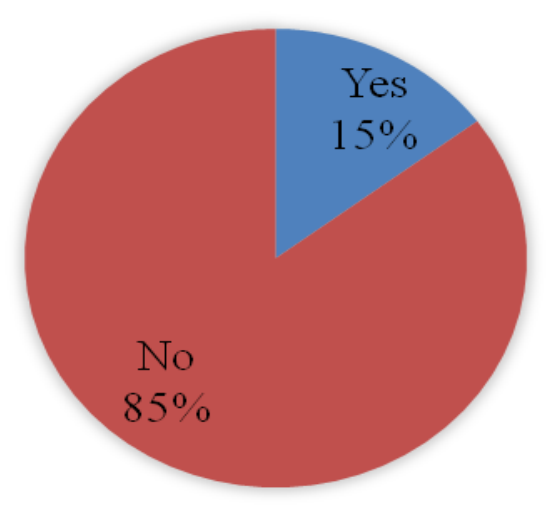

Fig.4 Dietary supplementation additional to their normal diet used both in adult dogs and puppies

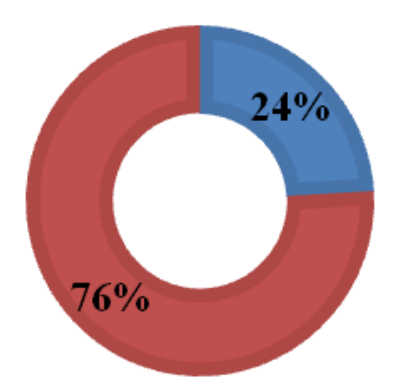

Yes $\square$ No 
Fig.5 Vitamin and mineral supplementation used both in adult dogs and in puppies

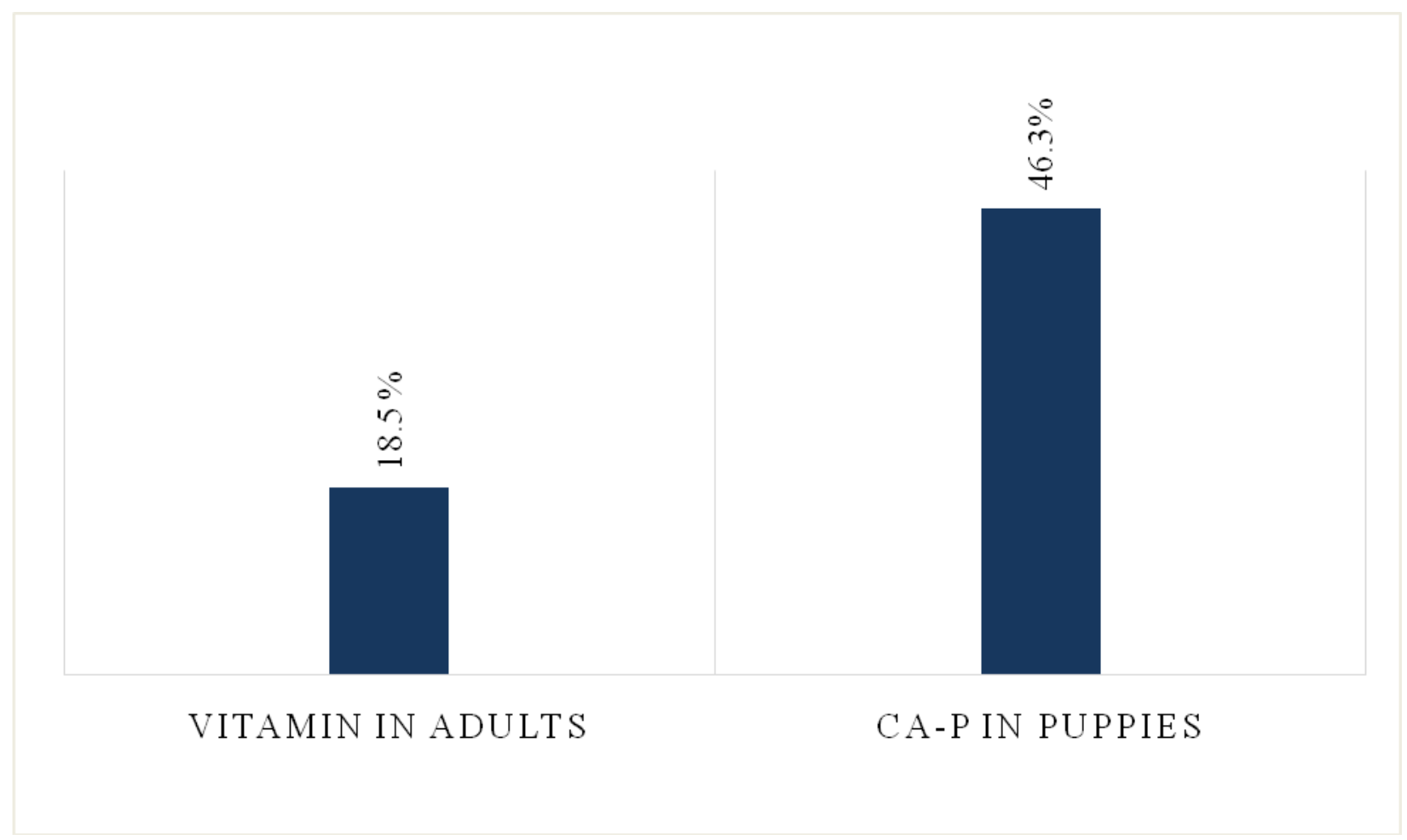

A study conducted by Rahaman and Yathiraj, (2000) revealed that dogs fed a homemade diet had a greater risk of health problems when compared to dogs fed a commercial diet. The present study also revealed that very few owners were aware of balanced feed for their pets (Fig. 3). Homemade diets that were preferred by the owners have a greater risk of health problems as compared to dogs fed nutritionally balanced commercial diets due to an imbalance of certain nutrients.

Only twenty-four percent of dogs received dietary supplements in addition to their normal diet. Whereas, puppies were receiving more $\mathrm{Ca}-\mathrm{P}$ supplements as compared to the adult dogs that were receiving about 18.5 percent vitamin supplements (Fig. 4 and 5). On these aspects it was observed that owners might recognize that homemade diets did not provide the optimum level of calcium for growth and supplements were easily available in the market and could be obtained without veterinary advice. The present study indicated that proper assessment of the dietary level of supplementation was required but due to lack of proper knowledge, owners were feeding Ca- P supplements. Increased dietary calcium during growth period above optimum level has been identified as a risk for the development of hip dysplasia and osteochondritis like diseases (Schoenmakers et al., 2000).

About 53.7 percent of dogs were fed milk as a separate meal and 18.5 percent of dogs were fed home prepared meat as protein source in addition to their normal diet. Owners were not well aware about lactose intolerance condition in case of adult dogs, so irrespective of that, they were providing a good quantity of milk to their dogs. Even though some studies have been demonstrated that with a successive increase in age there is a marked reduction in lactase production in the case of adult dogs (Zentek et al., 2002). 


\section{References}

Freeman, L. M., Abood, S. K., Fascetti, A. J., Fleeman, L. M., Michel, K. E. and Laflamme, D. P. et al., 2006. Disease prevalence among dogs and cats in the United States and Australia and proportions of dogs and cats that receive therapeutic diets or dietary supplements. Journal of the American Veterinary Medical Association, 229: 531-534.

Kraft, W. 1998. Geriatrics in canine and feline internal medicine. European Journal of Medical Research, 3: 31-41.

Laflamme, D. P., Abood, S. K., Fascetti, A. J., Fleeman, L. M., Freeman, L. M. and Michel, K. E. et al., 2008. Pet feeding practices of $\operatorname{dog}$ and cat owners in the United States and Australia. Journal of the American Veterinary Medical Association, 232: 687-694.

Rahaman, S. A. and Yathiraj, S. 2000. Commercial versus traditional food in canine health. Compendium on
Continuing Education for the Practicing Veterinarian 22, S97.

Schoenmakers, I. Hazewinkel, H. A., Voorhout, G. Carlson, C. S., and Richardson, D. 2000. Effects of diets with different calcium and phosphorus contents on the skeletal development and blood chemistry of growing great danes. The Veterinary Record. BMJ Publishing Group Limited 147, 652660.

Seneviratne, M., Subasinghe, D. W., and Watson, P. J. 2016. A survey of pet feeding practices of dog owners visiting a veterinary practice in Colombo, Sri Lanka. Veterinary medicine and science, 2(2):106-16.

Zentek, J., Marquart, B., and Pietrzak, T. 2002. Intestinal effects of mannanoligosaccharides, transgalactooligosaccharides, lactose and lactulose in dogs. Journal of Nutrition. American Society for Nutrition 132 (6 Suppl 2), 1682S1684 S.

\section{How to cite this article:}

Prabhjot Kaur Sidhu, Anant Simran Singh, Ankita Singla and Prabhjinder Singh. 2019. Canine Feeding Practices in Urban Punjab - A Concern. Int.J.Curr.Microbiol.App.Sci. 8(08): 115-120. doi: https://doi.org/10.20546/ijcmas.2019.808.014 